\title{
2D Seismic Imaging Improvement through Prestack Depth Migration (PSDM) Method
}

\author{
Iyod Suherman, Taufan Wiguna, Rahadian, Djunaedi Muljawan, Omar Moefti \\ Balai Teknologi Survei Kelautan, \\ Kedeputian Teknologi Pengembangan Sumberdaya Alam, \\ Badan Pengkajian dan Penerapan Teknologi, \\ Jl. M.H. Thamrin No. 8, Jakarta Pusat, Indonesia, 10340
}

(Received: April 10, 2018, Revised: October 30, 2018, Accepted: March 13, 2019 )

\begin{abstract}
The quality of seismic is important for interpretation. Prestack Depth Migration produce better quality of seismic imaging. The seismic generated through PSDM method has better seismic reflector and geological structure appearance compared to Prestack Time Migration (PSTM) method. Accurate interval velocity modeling is a key in PSDM process, involving dix transformation, coherency inversion, and tomography. Comparison between PSTM and PSDM show that PSDM offer better imaging for interpretation because PSDM has better seismic reflector continuity and good geological appearance.
\end{abstract}

Keywords: Prestack Depth Migration, PSDM, tomography, Dix transformation, coherency inversion,

\section{INTRODUCTION}

To generate the best interpretation and geological analysis should be done on seismic section in depth domain, meanwhile many seismic data processed in time domain. Seismic imaging generated in depth domain called Prestack Depth Migration (PSDM). According to Furniss [1] and Yimlaz [2], PSDM provide better subsurface geological imaging quality through minimize geological structure uncertainty compared to seismic in time domain (PSTM). In this paper we process and generate seismic in depth domain (PSDM) and compare to PSTM data.

\section{Prestack Depth Migration (PSDM)}

Prestack Depth Migration (PSDM) is the best method in seismic imaging technique and can handle area that has complex geological structure and cannot be done by Prestack Time Migration (PSTM). PSDM done in three main phases, the first is generate initial velocity model based on RMS velocity in PSTM seismic processing, the second one is generate interval velocity model use coherency inversion and dix transformation that derived from RMS velocity, and the third one is velocity model refinement use global tomography.

\section{Kirchhoff Migration}

One of the popular migration method is Kirchhoff migration [2][3] derived from wave equation based on Green's theorem. Mathematically, Kirchhoff migration written as:

$$
\begin{aligned}
& \psi\left(x_{0}, t\right)=\oint_{S 0}\left[\frac{4 \cos \theta}{v r}\left[\frac{\partial \psi}{\partial t}\right]_{(t+2 r / v)}\right] d_{\text {surf }} \\
& \psi\left(x_{0}, t\right)=\text { Kirchhoff difraction integral } \\
& v=\text { constant } \\
& r=\text { jarak bidang } \\
& t=\text { arrivall time } \\
& {\left[\frac{\partial \psi}{\partial t}\right]=\text { hyperbolic travel path }} \\
& d_{\text {surf }}=\text { surface difergence }
\end{aligned}
$$

The basic principle of Kirchhoff migration is summation all data points along diffraction curve and marking to the top of hyperbolic curve (fig.1).

\footnotetext{
* Corresponding author.

E-mail address: iyod.suherman@gmail.com
} 


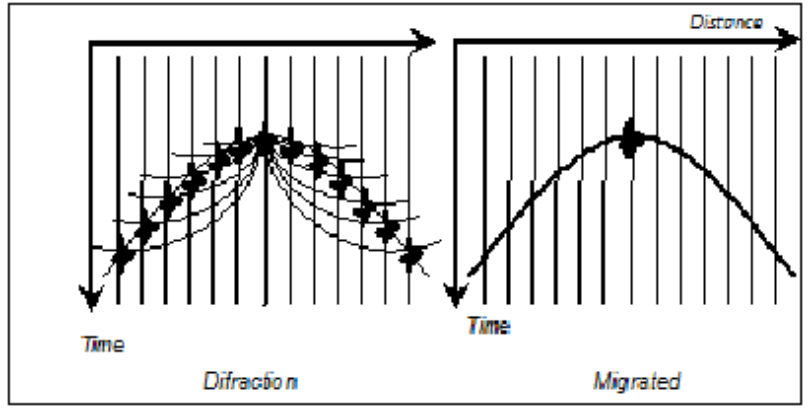

Figure 1. Kirchhoff Migration Principle (Yilmaz, 2001).

\section{Dix Transformation}

Interval velocity at certain depth calculated by Dix equation [4] derived from RMS equation, written as:

$V_{n}^{2}=\frac{V_{r m s_{n}}^{2} t(0)_{n}-V_{r m s_{n-1}}^{2} t(0)_{n-1}}{t(0)_{n}-t(0)_{n-1}}$

$V_{n}=$ interval velocity at layer $n$

$V_{\text {rms }}=$ RMSvelocity at layer $n$

$t(0)_{n}-t(0)_{n-1}=$ time interval

\section{Coherency Inversion}

Coherency inversion is a layer-stripping approach, therefore requires an interval velocity and depth model for all layers [1]. In this method, velocity on each layer generated from first layer to the next deeper layers by model travel time curves and compared to the data recorded on CMP seismic gathers.

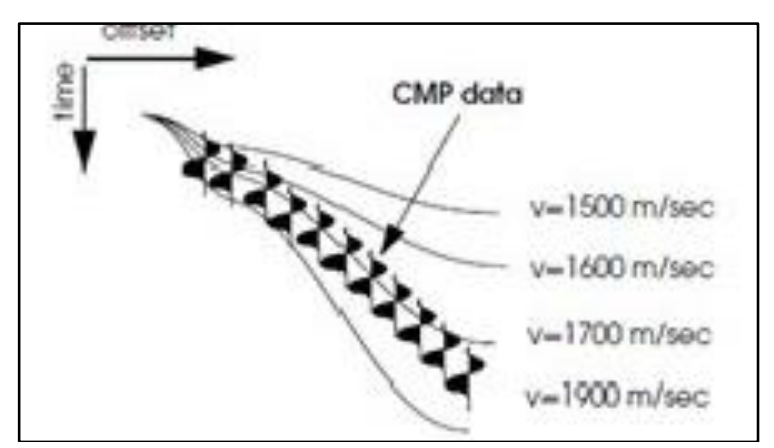

Figure 2. Coherency inversion principle (Furniss, 2000).

\section{Tomography}

Tomography is velocity modeling refinement method that corrects errors on velocity model by analyzing residual moveout. Figure 3 shows a simple subsurface model divided into nine rectangular each with its own constant velocity to illustrate the basic tomography principle [5].

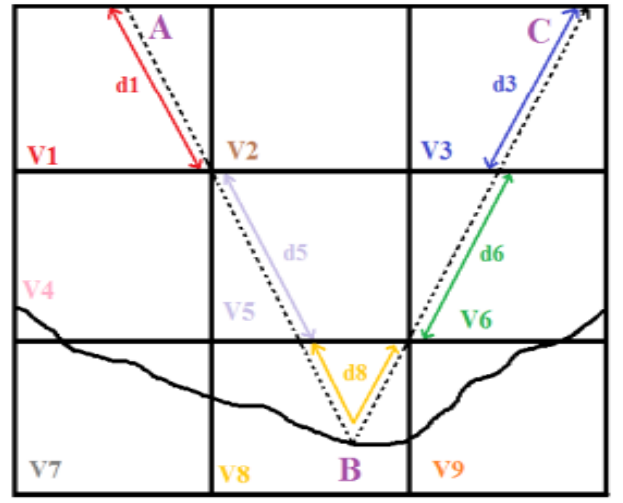

Figure 3. Simple tomography model (Fagin, 2002).

Arrival time for raypath $A B C\left(t_{A B C}\right)$, which is a raypath from $A$ (source) reflected on the dipping surface at $\mathrm{B}$ then arrived at $\mathrm{C}$ (receiver), written as:

$t_{A B C}=\frac{d_{1}}{v_{1}}+\frac{d_{5}}{v_{5}}+\frac{d_{8}}{v_{8}}+\frac{d_{6}}{v_{6}}+\frac{d_{3}}{v_{3}}$

Ray tracing is used in tomography algorithm to determine various possibility raypath and path length inside the rectangular box model. There are 2 type of tomography, grid-based tomography and horizon-based tomography [5]. In grid-based tomography, residual velocity correction in common reflection point (CRP) gathers are picked automatically by the software. Meanwhile horizonbased tomography the residual velocity correction are picked manual on each CRP by processor along the line.
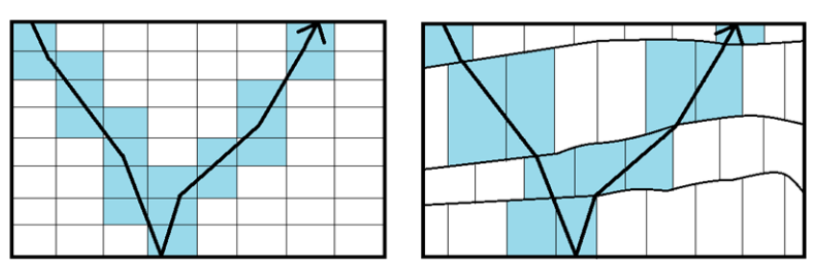

Figure 4. Grid-based tomography (left), Model-based tomography (right) (Fagin, 2002).

\section{METHOD}

Standard seismic data processing has been done for 2D seismic data in this paper, such as editing, filtering, velocity analysis and Prestack Time Migration (PSTM). From seismic data processing flow we have PSTM seismic section and RMS velocity, this RMS velocity then converted into interval velocity using Dix equation. These datas are used as input in inversion and tomography process to build depth-interval velocity model. Flowchart of PSDM processing shows in figure 5. 


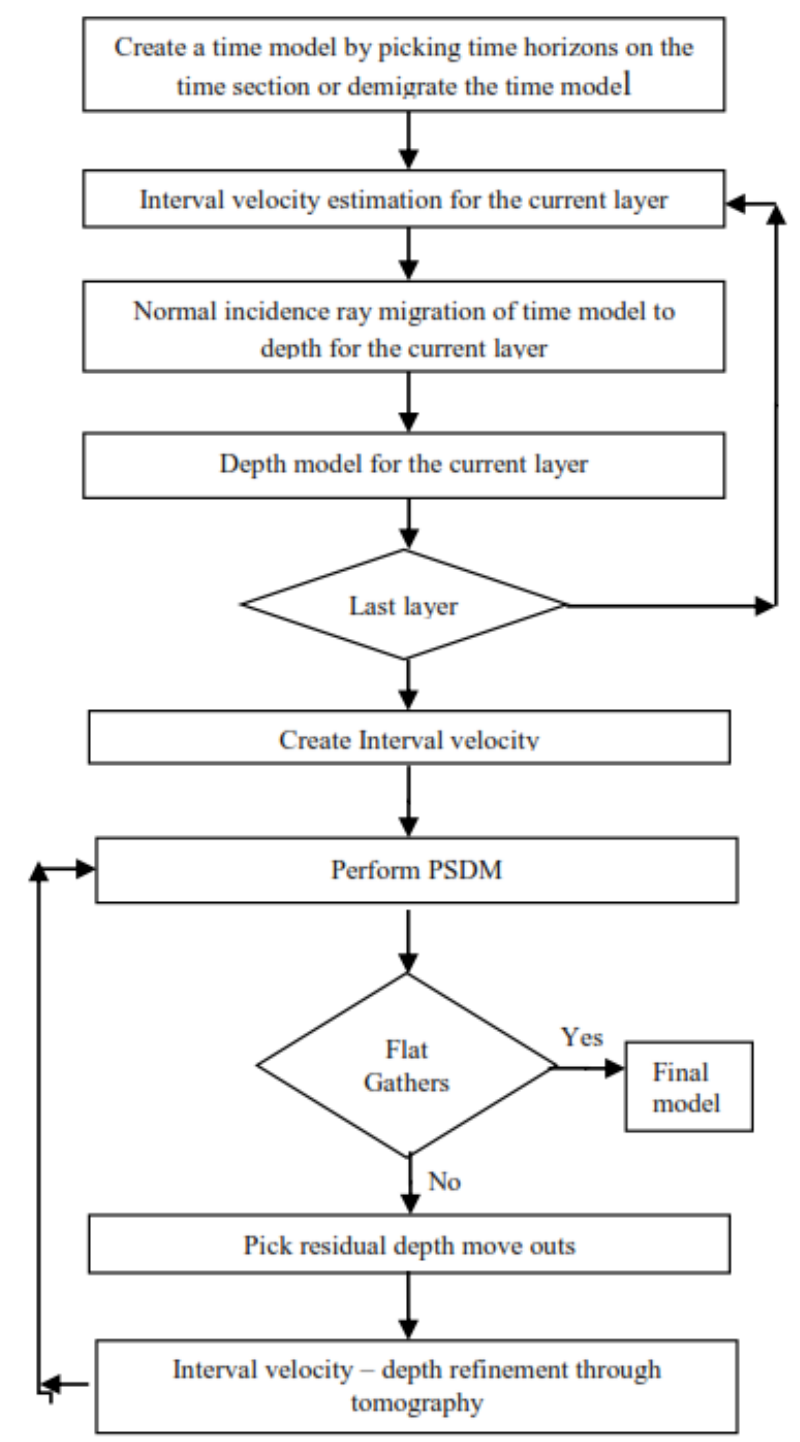

Figure 5. Flow chart of PSDM method [6].

\section{Data}

The data used in this research is $2 \mathrm{D}$ marine seismic data of North Madura Offshore. Acquisition parameter from observer report is used as parameter input in seismic data processing software, shown as below.

Table 1. Input parameter in data processing software

\begin{tabular}{|l|l|}
\hline Configuration & Off-end \\
\hline Source & $800 \mathrm{Cu} . \mathrm{In}$ \\
\hline Source Interval & $25 \mathrm{~m}$ \\
\hline Receiver Interval & $12.5 \mathrm{~m}$ \\
\hline Channels & 180 \\
\hline Near Offset & $100 \mathrm{~m}$ \\
\hline CDPs & 1510 \\
\hline
\end{tabular}

\section{RESULTS AND DISCUSSION}

The difference of migrated gather data before and after tomography shows in figure 6 . In this figure, the seismic amplitude marked by yellow line and red line looks more flat after tomography applied, it is mean that velocity model from tomography process is good enough to applied in the next PSDM process.

Final result of PSDM seismic section compared to PSTM seismic section (figure 7) shows seismic reflector continuity enhancement and shows better fault appearance on PSDM seismic section (marked by yellow circle).

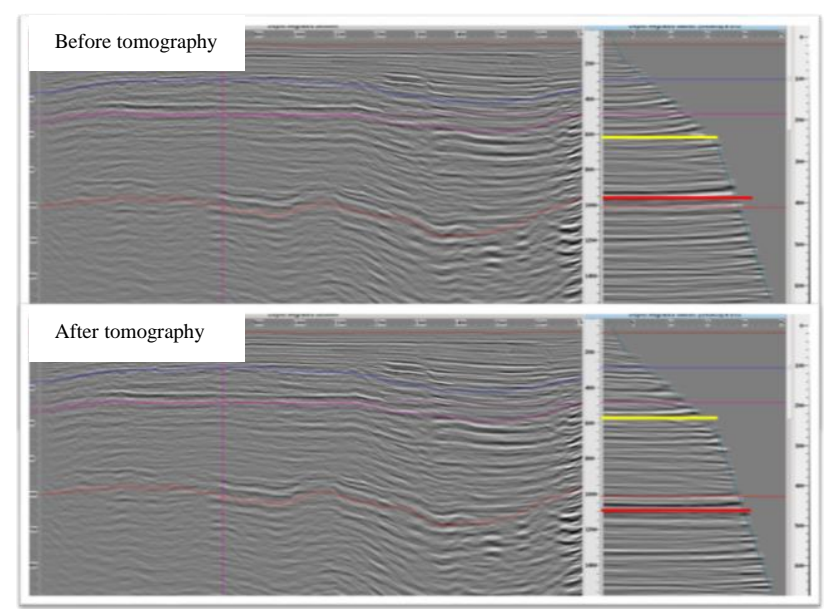

Figure 6. Comparison between velocity model refinement before (top) and after tomography (bellow).

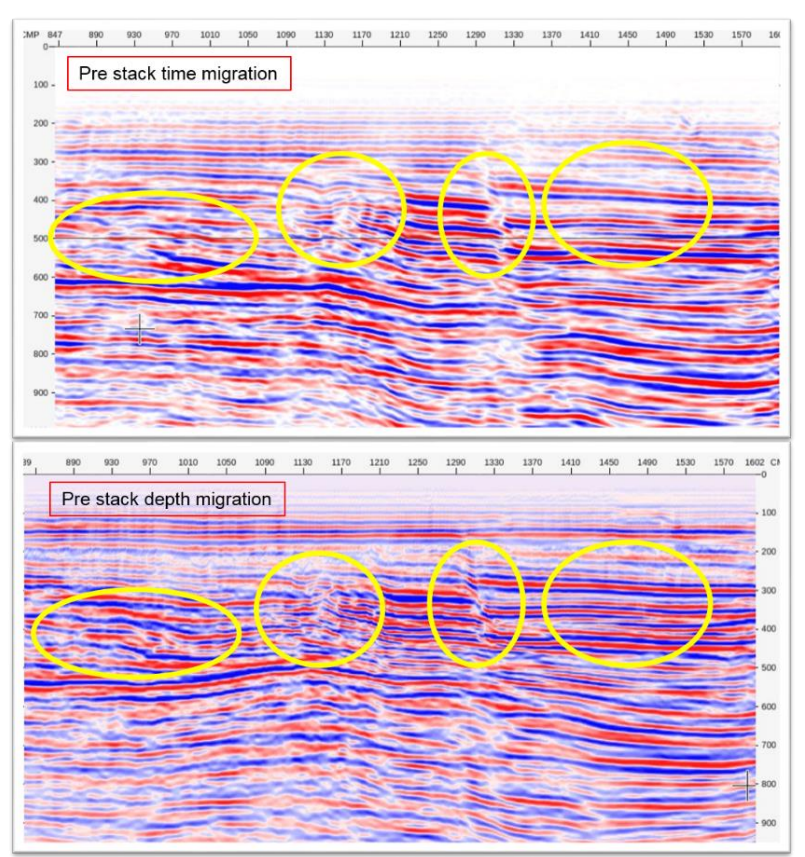

Figure 7. Comparison between PSTM seismic section (top) and PSDM seismic section (bellow)

\section{CONCLUSION}

Prestack Depth Migration method results a better seismic imaging and accurate compared to Prestack Time Migration (PSTM). On the final result of this research, it shows better seismic reflector continuity, stronger seismic event in some areas and appearance geological structure clearly 
such as fault structure. It is mean PSDM method has an important role in enhancement the quality of subsurface imaging.

\section{REFERENCES}

[1] Furniss, A., An integrated PreSDM workflow using model-based velocity estimation and refinement. Geohorizons (2000).

[2] Yilmaz, O., Seismic Data Analysis, Vol-1\& 2 (Text), SEG Publication (2001).

[3] Schneider, W.A., Integral formulation for migration in two dimensions or three dimensions. Geophysics, 43, 49-76 (1978).

[4] Dix, C.H., Seismic Velocities from Surface Measurements. Geophysics, 20, 68-86 (1955).

[5] Fagin, S., Model-based depth imaging, SEG Course Notes Series No.10 (2002).

[6] Mahadasu, P., Singh, K.H., Improved Seismic Imaging through Prestack Depth Migration using Synthetic Seismic Data, GSTF Journal of Geological Sciences Vol.2 No.1 (2015). 